\title{
ASSESSMENT OF SEPTOPLASTY OUTCOME USING NASAL OBSTRUCTION SYMPTOM EVALUATION SCALE
}

\author{
Shrestha KK, Joshi RR, Rijal AS, Dhungana A, Maharjan S
}

Department of Otolaryngology, Head and Neck surgery, Nepal Medical College and Teaching Hospital, Attarkhel, Gokarneshwor-8, Kathmandu, Nepal

\begin{abstract}
Nasal obstruction, the most common presenting symptom in nasal and sinus disease, is defined as patient discomfort manifested as a sensation of insufficient airflow through the nose. Nasal septal deviation is the most common anatomical cause of nasal obstruction. Surgical correction of a deviated septum, nasal septoplasty, is the definitive treatment for septal deviation. Many studies have discussed about outcomes of septoplasty. However, there is limited published literature on nasal septoplasty and its outcome in Nepal. The aim of this study is to evaluate the outcome of septoplasty using Nasal Obstruction Symptom Evaluation (NOSE) scale, a validated outcome instrument assessing quality of life (QoL) related to nasal obstruction. A total of 52 patients aged 18 years and above, with nasal obstruction at least for 3 months, undergoing septoplasty alone were included in the study. Baseline NOSE score was calculated a week before surgery. The patients were followed up after 3 months to record postoperative NOSE score. On statistical analysis, the mean NOSE scores before and 3 months after septoplasty were $45.58 \pm 21.38$ and $8.46 \pm 8.37$ respectively. The mean difference was $37.11 \pm 21.22$ and $p$ value on paired t test was less than 0.001 (highly significant). The mean differences of each component of the NOSE scale questionnaire were also found to be highly significant statistically with $\mathrm{p}$ values less than 0.001 . Gender and age did not seem to affect the outcomes. In conclusion, NOSE scale is a valid, reliable and responsive instrument that is brief and easy to complete and has potential use for outcome studies in adults with nasal obstruction. This instrument showed that septoplasty, if done in properly selected patients, results in significant improvement in nasal obstruction and disease specific quality of life with high patient satisfaction.
\end{abstract}

\section{KEYWORDS}

Septoplasty, nasal obstruction,

NOSE scale

\section{CORRESPONDING AUTHOR}

Dr. Kundan Kumar Shrestha

Assistant Professor,

Dept of Otolaryngology \& Head and Neck Surgery,

Nepal Medical College and Teaching Hospital, Attarkhel, Gokarneshwor-8, Kathmandu, Nepal

Email: kundanshrestha9@hotmail.com 


\section{INTRODUCTION}

Nasal obstruction is the most common presenting symptom in nasal and sinus disease. ${ }^{1}$ It is commonly defined as patient discomfort manifested as a sensation of insufficient airflow through the nose. ${ }^{2}$ The etiology of nasal obstruction is generally divided into mucosal and anatomical causes. Nasal septal deviation is the most common anatomical cause of nasal obstruction. ${ }^{3}$ About $80 \%$ of the general population has a deviated nasal septum to some degree. ${ }^{4}$ Other common causes include mucosal congestion, turbinate hypertrophy, adenoid hypertrophy and nasal mass. Surgical correction of a deviated septum, nasal septoplasty, is the definitive treatment for septal deviation..$^{5,6}$ It is also the most common ear, nose and throat (ENT) operation in adults. $^{7}$

Nasal septal deviation may be congenital, as a part of a damaging process during in-utero development or during birth, or acquired, as a result of a traumatic impact in childhood or adult life. Childhood trauma brings more damage to the growing septum. These patients may present with a history of sinusitis, allergic rhinitis, obstructive sleep apnoea, atypical facial pain, previous nasal surgery or recent nasal trauma. They often complain of unilateral or bilateral nasal obstruction that is not relieved with nasal decongestants or steroid nasal sprays. ${ }^{8}$ If there is a visible nasal septal deviation with no other identifiable causes, septoplasty needs to be done in them. The indications for septoplasty vary. Nasal obstruction, crusting, rhinorrhea, postnasal discharge, recurrent sinus pressure or pain, epistaxis, headache, snoring and sleep apnoea are mentioned as indications for septoplasty. ${ }^{9}$ It can also be done to provide an access for FESS, as a part of cosmetic rhinoplasty and to access a pituitary tumour via the nose.

Many studies have discussed about outcomes of septoplasty. ${ }^{10-16}$ However, there is limited published literature on nasal septoplasty and its outcome in Nepal. This study attempts to fill that void. The aim of this study is evaluation of septoplasty outcome using NOSE (Nasal Obstruction Symptom Evaluation) scale. The NOSE scale is a validated outcome instrument assessing quality of life (QoL) related to nasal obstruction (Table 1). ${ }^{5,6}$

\section{MATERIAL AND METHODS}

This prospective study was carried out at the department of Otolaryngology Head and Neck Surgery, Nepal Medical College and Teaching Hospital (NMCTH), Attarkhel, Kathmandu, Nepal from July 2017 to December 2018. Ethical approval was taken from the Institutional Review Committee (IRC) of NMCTH. Prior informed written consent was taken from all the subjects participating in the study. Inclusion criteria were as follows: at least 18 years old, septal deviation consistent with nasal obstruction at least for 3 months, persistent symptoms even after 4 weeks of medical management with nasal steroid, antihistaminic and/or oral decongestants. Exclusion criteria were as follows: sinonasal malignancy, septoplasty done along with other surgeries such as endoscopic sinus surgery, nasal valve surgery, turbinate surgery or as an approach to pituitary tumours, sinonasal infections, sinonasal inflammatory disease, prior nasal surgery, septal perforation, craniofacial syndrome, nasal trauma, fracture, adenoid hypertrophy and coexisting debilitating diseases/major systemic diseases. The consultant faculty members decided for indication of septoplasty operation with patients by doing a complete ENT examination. Baseline NOSE score was calculated a week before surgery. The patients were followed up for a minimum period of 3 months to record postoperative symptom improvement rate by NOSE scale at the end of 3 months. The results of our study were analyzed on SPSS-17 using "paired t test”.

\section{RESULTS}

A total of 52 patients were included in the study of which $31(59.6 \%)$ were males while $21(40.4 \%)$ were females with male to female ratio of 1.4:1. Genderwise, the preoperative NOSE score was more in females $(48.33 \pm 22.93)$ compared to males (43.71 \pm 20.45$)$. Both males and females showed statistically significant improvement in mean NOSE scores after septoplasty with $\mathrm{p}$ values less than 0.001 for both groups while applying paired t test (Table 2).

Table 1: The NOSE scale

Over the past one month, how much of a problem were the following conditions for you?

Please circle the most correct response

1. Nasal congestion or stuffiness

2. Nasal blockage or obstruction

3. Trouble breathing through nose

4. Trouble sleeping

5. Unable to get enough air through 5. nose during exercise or exertion

\section{Not a problem}

\section{0}

0

0

0

0
Very mild
problem

1
1
1
1
1

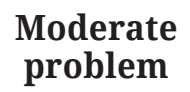

2

2

2

2

2
Fairly severe
problem

3

3

3

3

3
Severe problem

4 
Table 2: Genderwise comparison of NOSE scores before and 3 months after septoplasty

\begin{tabular}{lcccc} 
Gender & Preoperative Mean \pm SD & Postoperative Mean \pm SD & Difference Mean \pm SD & p value \\
Males $(\mathrm{n}=31)$ & $43.71 \pm 20.45$ & $6.94 \pm 8.33$ & $36.77 \pm 21.03$ & $<0.001$ \\
Females $(\mathrm{n}=21)$ & $48.33 \pm 22.93$ & $10.71 \pm 8.10$ & $37.61 \pm 22.00$ & $<0.001$ \\
Total=52 & & & & \\
\hline
\end{tabular}

Table 3: Agewise comparison of NOSE scores before and 3 months after septoplasty

\begin{tabular}{lcccc} 
Age range & $\begin{array}{c}\text { Preoperative } \\
\text { Mean } \pm \text { SD }\end{array}$ & $\begin{array}{c}\text { Postoperative } \\
\text { Mean } \pm \text { SD }\end{array}$ & $\begin{array}{c}\text { Difference } \\
\text { Mean } \pm \text { SD }\end{array}$ & p value \\
$\leq 30$ years $(n=34)$ & $44.85 \pm 20.76$ & $7.21 \pm 7.99$ & $37.64 \pm 21.71$ & $<0.001$ \\
31 to 45 years $(n=11)$ & $41.82 \pm 26.29$ & $9.09 \pm 8.89$ & $32.72 \pm 22.06$ & 0.001 \\
$>45$ years $(n=7)$ & $55 \pm 15.27$ & $13.57 \pm 8.52$ & $41.42 \pm 19.08$ & 0.001 \\
Total $=52$ & & & & \\
\hline
\end{tabular}

The ages of patients ranged from 19 to 60 years with a mean age of $30.3 \pm 10.9$ years. Majority of the patients $(65.4 \%)$ were below 31 years. The mean NOSE score before septoplasty was highest in $>45$ years age group $(55 \pm 15.27)$. All three age groups ( $<30$ years, 31 to 45 years and $>45$ years) showed statistically significant improvement in mean NOSE scores after septoplasty (Table 3 ).

The overall preoperative NOSE scores of all the patients were compared to the post-operative NOSE scores to know the functional outcome of the surgical procedure. On statistical analysis, the mean NOSE scores before and 3 months after septoplasty were $45.58 \pm 21.38$ and $8.46 \pm 8.37$ respectively. When paired t test was calculated, the mean difference was $37.11 \pm 21.22$ and $t$ value was 12.61 which was highly significant $(p<0.001)$. The mean differences of each component of the NOSE scale questionnaire were also compared before and after surgery and were found to be highly significant statistically with $\mathrm{p}$ values less than 0.001 for all the components (Table 4).

\section{DISCUSSION}

Septoplasty is a surgical procedure done to correct the deviated nasal septum. At present, otorhinolaryngologists usually consider nasal obstruction to be the chief indication to perform septoplasty. Although the literature shows a prevalence of nasal septal deviation in up to $80 \%$ of population, in clinical practice, however, only a minority of individuals is actually found to suffer from nasal obstruction. Literature also suggests that there are not many scientific publications on the effects of septoplasty and most of them are inconclusive indicating that there is paucity of hard evidence as to whether this procedure actually provides any benefit to the patient. ${ }^{17}$ Currently, the effectiveness of septoplasty in adults with nasal obstruction and a deviated nasal septum remains uncertain.

Nasal complaints can be assessed by many disease-specific QoL questionnaires available in literature like the "Chronic Sinusitis Survey (CSS)",

Table 4: Comparison of components of NOSE score before septoplasty and at 3 months follow up

\begin{tabular}{lcccc} 
Components of NOSE & $\begin{array}{c}\text { Preoperative } \\
\text { Mean } \pm \text { SD }\end{array}$ & $\begin{array}{c}\text { Postoperative } \\
\text { Mean } \pm \text { SD }\end{array}$ & $\begin{array}{c}\text { Difference } \\
\text { Mean } \pm \text { SD }\end{array}$ & p value \\
Nasal congestion & $2.12 \pm 0.73$ & $0.77 \pm 0.58$ & $1.34 \pm 0.78$ & \\
Nasal blockage & $2.15 \pm 0.89$ & $0.52 \pm 0.61$ & $1.63 \pm 0.9$ & \\
$\begin{array}{l}\text { Trouble breathing through } \\
\text { nose }\end{array}$ & $1.83 \pm 1.04$ & $0.21 \pm 0.41$ & $1.61 \pm 1.08$ & \\
Trouble sleeping & $1.48 \pm 1.05$ & $0.08 \pm 0.26$ & $1.40 \pm 1.05$ & $<0.001$ \\
$\begin{array}{l}\text { Unable to get enough air } \\
\text { through nose during exercise }\end{array}$ & $1.54 \pm 1.09$ & $0.13 \pm 0.34$ & $1.40 \pm 1.14$ & \\
Total score (out of 100) & $45.58 \pm 21.38$ & $8.46 \pm 8.37$ & $37.11 \pm 21.22$ & \\
\hline
\end{tabular}


the "Rhinosinusitis Disability Index (RSDI)", the "Sino-Nasal Outcome Test (SNOT-20)", the "Rhinoconjunctivitis Quality of Life Questionnaire (RQLQ)", and the "Allergy Outcome Survey (AOS)". However, none of these is specific to assess the nasal obstruction only. The CSS, the RSDI and the SNOT-20 were made to assess the chronic rhinosinusitis whereas the RQLQ and the AOS were mainly designed for allergic rhino-conjunctivitis. These questionnaires have some relationship in showing the nasal obstruction, but still fail to meet the necessity to have a specific instrument for nasal obstruction. ${ }^{18-23}$ Therefore, the NOSE questionnaire was designed to assess the specific QoL associated with the nasal obstruction. It is a simple and fast questionnaire to answer. Its score varies between 0 and 100, with higher scores meaning greater nasal obstruction. ${ }^{6}$

In our study, females showed slightly higher mean NOSE scores both before and after septoplasty compared to males though not significant statistically. This might be a result of greater concern of health among females. However, both genders showed statistically significant improvement in mean NOSE scores after septoplasty with $p$ values less than 0.001 for both groups. Majority of the patients (65.4\%) in our study were below 31 years. This corresponds to the most productive years of an individual and therefore is quite understandably the period when one would want to have the best of health and quality of life. The mean NOSE scores before and after septoplasty were highest in $>45$ years age group though not significant statistically. However, all three age groups ( $\leq 30$ years, 31 to 45 years and $>45$ years) showed statistically significant improvement in mean NOSE scores after septoplasty. These findings were comparable to several other studies which showed that age range or gender did not influence septoplasty outcomes. ${ }^{5,24,25}$

Multiple physiological and psychological factors affect patients' perception of nasal obstruction. The perception of nasal obstruction and outcomes of surgery also depend on operative technique, conditions of vascular and nerve supplies and expectations of patients from surgery. ${ }^{24}$ In our study, all patients showed very significant improvement in nasal obstruction at 3 months. Similar results were obtained in other studies., ${ }^{5,13,24,26-28}$ Although our sample size was small, our results show that the effect of septoplasty in improving nasal obstruction is very powerful. This could be due to very precise patient selection for septoplasty in our institution where we choose to perform septoplasty only on grossly deviated nasal septum causing troublesome subjective nasal obstruction. Some investigators believe that, regardless of the magnitude of septal deviation, most patients benefit from its surgical correction because it eliminates a possible contributing factor to the pathogenesis of chronic rhinosinusitis. ${ }^{29}$ This factor could also be taken into consideration for such high level of satisfaction achieved in our study. Nevertheless, inappropriate selection of surgery as a therapeutic option and inappropriate choice of surgical modality do seem to be major causes for dissatisfaction. ${ }^{30,31}$
The coexistence of allergy or sinonasal disease with septal deviation is also statistically associated with higher rates of dissatisfaction after surgery. ${ }^{10}$ Because we excluded septoplasties done along with any other surgeries and included only those patients with nasal obstruction who failed a prior 4 week trial of medical management with nasal steroid, antihistaminic and/or oral decongestants, these possible sources of dissatisfaction were eliminated to a large extent in our study. This could also be another reason for high level of satisfaction observed in our study.

It is important to highlight that the prospective design, the use of a validated questionnaire, patient assessment based on results and the lack of follow up losses were the strengths of our study.

The use of a small non-randomized sample, single institutional set up and lack of long term follow up can be considered as limitations of our study. In future, larger multicentric studies with randomised probabilistic sampling process and long term follow up protocols could influence the result, its external validity and and help us understand better about the outcomes of septoplasty in treating nasal obstruction. One of the weaknesses of our study is also the lack of a control group. However, there is no alternative treatment for a deviated nasal septum other than surgical correction, so clinical equipoise does not allow for randomization away from septoplasty to sham or placebo surgery or nonsurgical treatment. ${ }^{5,26}$ of course, the inclusion criteria used in our study required that medical therapy had failed for each patient; therefore, all patients in the study had a trial of nonsurgical treatment before septoplasty.

In conclusion, nasal obstruction is one of the symptoms which is hard to evaluate. NOSE scale could be used for the evaluation of this symptom. NOSE scale is a valid, reliable and responsive instrument that is brief and easy to complete and has potential use for outcome studies in adults with nasal obstruction. This instrument showed that septoplasty, if done in properly selected patients, results in significant improvement in nasal obstruction and disease specific QoL with high patient satisfaction.

\section{REFERENCES}

1. Kim CS, Moon BK, Jung DH, Min Y-G. Correlation between nasal obstruction symptoms and objective parameters of acoustic rhinometry and rhinomanometry. Auris Nasus Larynx 1998; 25: 458.

2. Jessen M, Malrn L. Definition, prevalence and development of nasal obstruction. Allergy 1997; 52: 3-6.

3. Sipilä J, Suonpää J. A prospective study using rhinomanometry and patient clinical satisfaction to determine if objective measurements of nasal airway resistance can improve the quality of 
septoplasty. Eur Arch Otolaryngol 1997; 254: 38790.

4. Gray LP. Deviated nasal septum incidence and etiology. Ann Otol Rhinol Laryngol 1978 (Suppl); 87: 3-20.

5. Stewart MG, Smith TL, Weaver EM et al. Outcomes after nasal septoplasty: results from the Nasal Obstruction Septoplasty Effectiveness (NOSE) study. Otolaryngol Head Neck Surg 2004; 130: 28390.

6. Stewart MG, Witsell DL, Smith TL, Weaver EM, Yueh B, Hannley MT. Development and validation of the Nasal Obstruction Symptom Evaluation (NOSE) scale. Otolaryngol Head Neck Surg 2004; 130: 157-63.

7. Manoukian PD, Wyatt JR, Leopold DA, Bass EB. Recent Trends in Utilization of Procedures in Otolaryngology-Head and Neck Surgery. Laryngoscope 1997; 107: 472-7.

8. Karatzanis AD, Fragiadakis G, Moshandrea J, Zenk J, Iro H, Velegrakis GA. Septoplasty outcome in patients with and without allergic rhinitis. Rhinology 2009; 47: 444-9.

9. Olphen AFV. The Septum. In: Gleeson M, editors. Scott Brown's Otorhinolaryngology, Head and Neck Surgery (7 ed.). Great Britain. Hodder Arnold; 2008: 1569-81.

10. Jessen M, Ivarsson A, Malm L. Nasal airway resistance and symptoms after functional septoplasty: comparison of findings at 9 months and 9 years. Clin Otolaryngol 1989; 14: 231-4.

11. Samad I, Stevens H, Maloney A. The efficacy of nasal septal surgery. J Otolaryngol 1992; 21: 88-91.

12. Siegel NS, Gliklich RE, Taghizadeh F, Chang Y. Outcomes of septoplasty. Otolaryngol Head Neck Surg 2000; 122: 228-32.

13. Arunachalam P, Kitcher E, Gray J, Wilson J. Nasal septal surgery: evaluation of symptomatic and general health outcomes. Clin Otolaryngol 2001; 26: 367-70.

14. Broms P, Jonson B, Malm L. Rhinomanometry. IV. A pre-and postoperative evaluation in functional septoplasty. Acta Otolaryngol 1982; 94: 523-9.

15. Pirilä T, Tikanto J. Unilateral and bilateral effects of nasal septum surgery demonstrated with acoustic rhinometry, rhinomanometry, and subjective assessment. Am J Rhinol 2001; 15: 127-33.

16. Hwang PH, Mclaughlin RB, Lanza DC, Kennedy DW. Endoscopic septoplasty: indications, technique, and results. Otolaryngol Head Neck Surg 1999; 120: 678-82.

17. Roblin DG, Eccles R. What, if any, is the value of septal surgery? Clin Otolaryngol Allied Sci 2002; 27: 77-80.
18. Gliklich RE, Metson R. Techniques for outcomes research in chronic sinusitis. Laryngoscope 1995; 105: 387-90.

19. Benninger MS, Senior BA. The development of the Rhinosinusitis Disability Index. Arch Otolaryngol Head Neck Surg 1997; 123: 1175-9.

20. Piccirillo JF, Merritt MG Jr, Richards ML. Psychometric and clinimetric validity of the 20-Item Sino-Nasal Outcome Test (SNOT-20). Otolaryngol Head Neck Surg 2002; 126: 41-7.

21. Juniper EF, Guyatt GH. Development and testing of a new measure of health status for clinical trials in rhinoconjunctivitis. Clin Exp Aller 1991; 21: 77-83.

22. Kemker BJ, Corey JP, Branca J, Gliklich RE. Development of the allergy outcome survey for allergic rhinitis. Otolaryngol Head Neck Surg 1999; 121: 603-5.

23. Rhee JS, Book DT, Burzynski M, Smith TL. Quality of life assessment in nasal airway obstruction. Laryngoscope 2003; 113: 1118-22.

24. Konstantinidis I, Triaridis S, Triaridis A, Karagiannidis K, Kontzoglou G. Long term results following nasal septal surgery focus on patient's satisfaction. Auris Nasus Larynx 2005; 32: 369-74.

25. Lindemann J, Tsakiropoulou E, Konstantinidis I, Lindemann K. Normal aging does not deteriorate nose-related quality of life: Assessment with "NOSE" and "SNOT-20" questionnaires. Auris Nasus Larynx 2010; 37: 303-7.

26. Gandomi B, Bayat A, Kazeimei T. Outcome of Septoplasty in Young Adults: The Nasal Obstruction Septoplasty Effectiveness Study. Am J Otolaryngol 2010; 31: 189-92

27. Kahveci OK, Miman MC, Yucel A, Yucedag F, Okur E, Altuntas A. The efficiency of Nose Obstruction Symptom Evaluation (NOSE) scale on patients with nasal septal deviation. Auris Nasus Larynx 2012; 39: 275-9.

28. Mondina M, Marro M, Maurice S, Stoll D, de Gabory L. Assessment of nasal septoplasty using NOSE and RhinoQoL questionnaires. Eur Arch Otolaryngol 2012; 269: 2189-95.

29. Elahi MM, Frenkiel S: Septal deviation and chronic sinus disease. Am J Rhinol 2000; 14: 175-9.

30. Dinis PB, Haider H. Septoplasty: long-term evaluation of results. Am J Otolaryngol 2002; 23: 85-90.

31. Gordon AS, McCaffrey TV, Kern EB, Pallanch JF. Rhinomanometry for preoperative and postoperative assessment of nasal obstruction. Otolaryngol Head Neck Surg 1989; 101: 20-6. 